\title{
Reusing intravaginal progesterone releasing devices for oestrous synchoronization in ewes
}

\author{
Y.I. Rodríguez-Sánchez ${ }^{1}$, M.T. Sánchez-Torres ${ }^{1 \#, ~ J . L . ~ C o r d e r o-M o r a 1, ~ J . L . ~ F i g u e r o a-V e l a s c o ", ~}$ \\ J. Cortés-Zorrilla ${ }^{2}$, J.A. Martínez-Aispuro ${ }^{1} \&$ M. Cardenas-León ${ }^{3}$ \\ ${ }^{1}$ Programa de Ganadería Colegio de Postgraduados, Campus Montecillo, Texcoco, Estado de México, México. \\ ${ }^{2}$ Departamento de Biología de la Reproducción, Universidad Autónoma Metropolitana, Ciudad de México, México. \\ ${ }^{3}$ Laboratorio de Biología de la Reproducción, Instituto Nacional de Ciencias Médicas y Nutrición, Tlalpan, Ciudad de
} México, México.

(Submitted 23 September 2019; Accepted 5 January 2020; First published online 8 September 2020)

Copyright resides with the authors in terms of the Creative Commons Attribution 4.0 South African Licence.
See: http://creativecommons.org/licenses/by/4.0/za
Conditions of use: The user may copy, distribute, transmit and adapt the work, but must recognise the authors and the South African
Journal of Animal Science.

\begin{abstract}
In this study, the second use of an intravaginal progesterone-releasing device or controlled intravaginal drug release device (CIDR) was evaluated. After a first use of 11 days, the CIDR was again used for either nine or 12 days with 200 or $300 \mathrm{IU}$ equine chorionic gonadotrophin (eCG) being injected on its removal. Sixty-four ewes were randomly distributed to four treatments ( $n=16 /$ group): CIDR9+eCG200, CIDR9+eCG300, CIDR12+eCG200, and CIDR12+eCG300. The eCG was administered intramuscularly on withdrawal of the device. Thus, the experiment was a completely randomized design with a $2 \times 2$ factorial arrangement of treatments. Oestrus presentation did not differ between treatments $(P=0.29)$. However, with the dose of $200 \mathrm{IU}$ of eCG, oestrus presentation tended to increase $(P=0.08)$. The onset and duration of oestrus, percentage of gestation, and return to oestrus did not differ between treatments $(P>0.05)$. Progesterone concentration in serum was greater $(P<0.05)$ in ewes treated with CIDR12+eCG300. Prolificacy was greatest (1.44) with the CIDR12+eCG300 treatment and was different $(P=0.001)$ from the treatments CIDR9+eCG200 (1.21) and CIDR9+eCG300 (1.20), but not from the CIDR12+eCG200 treated ewes (1.31). The CIDR12+eCG300 treatement produced the highest percentage of twin births (45.8\%) $(P$ $=0.001)$. Leaving the device in place for 12 days increased $(P=0.001)$ the incidence of twin births. Use of the CIDR for a second time synchronized oestrus in ewes successfully with better fertility being obtained when the device was left in place for 12 days, and 300 IU of eCG was injected on its removal.
\end{abstract}

Key words: gonadotropin, progesterone device, synchronization

\#Corresponding author: teresa@colpos.mx

\section{Introduction}

Oestrous synchronization has been used for a long time. However, with the increase in knowledge of the dynamics of follicular development (Ginther et al., 1995), experiments have been focused on concentrating the oestrus period to a shorter time if artificial insemination is desired. On the other hand, with the increasing demand to be environmentally friendly and with the costs to the producers in mind, efforts have focused on reusing progesterone-releasing devices without affecting their efficiency, and making their use more affordable.

To improve the profitability of intensive sheep production, it is necessary to increase reproductive efficiency by increasing fertility, prolificacy and the frequency of births. Reproductive seasonality in sheep is a limiting factor to achieving the goal of three parturitions in two years (Rosa et al., 2003). To overcome this limitation various reproductive strategies have been studied. These include treatments with exogenous hormones and their synthetic analogues, melatonin implants either separately or in combination (Abecia et al., 2011). These treatments induce and synchronize ovulation and oestrus in the reproductive period or during the periods of reproductive transition and anoestrus with varying degrees of success (Abecia et al., 2012; Laven, 2019). 
Controlled intravaginal release devices with natural progesterone $\left(\mathrm{P}_{4}\right)$ stimulate the induction and synchronization of oestrus for a prolonged time (from 12 to 14 days) in ewes (Wheaton et al., 1993; Escobar et al., 2017; Menchaca et al., 2017). This increases the percentage of ewes in oestrus, but with variable effects on fertility (Menchaca \& Rubianes, 2004). Controlled intravaginal release devices provide a high serum $\mathrm{P}_{4}$ concentration immediately after insertion because of their efficient kinetic release, which falls dramatically after the removal of the device, but with no cumulative effect (Mohan, 2017). Prolonged exposure to $\mathrm{P}_{4}$ in hormonal procedures normally increases the diameter of the ovulatory follicle, but decreases the number of ovulatory follicles (Bartlewski et al., 2017). To reduce the negative effect of long procedures, reproductive effectiveness has been evaluated with medium (8 to 10 days) and short (5 to 7 days) protocols using intravaginal devices to synchronize oestrus in ewes (Martinez-Ros et al., 2019b; Swelum et al., 2016; Swelum et al., 2018a).

For progesterone treatment to be effective, an adequate amount of gonadotropin is necessary to trigger preovulatory events, so when the CIDR device is removed, eCG is injected to result in similar functions to follicle-stimulating hormone (FSH) and luteinizing hormone (LH) (Murphy, 2012; Martinez-Ros et al., 2019a). Equine chorionic gonadotrophin can also be used to accelerate puberty, induce oestrus, improve fertility, induce multiple ovulation for embryo transfer procedures, and induce a greater synchrony of ovulation in sheep (Ramos \& Silva, 2018). The application of eCG after the removal of the CIDR ensures the occurrence of fertile ovulations (Martinez-Ros et al., 2019b; Uriol et al., 2019), reduces the interval from oestrus to ovulation, and increases the corpus luteum (CL) diameter (Cox et al., 2012). Generally, recommended doses of eCG vary from 250 to 500 IU zBarret et al., 2004), depending on weight, age (250300 in young ewes, 350 - $500 \mathrm{IU}$ in adult ewes), season (400 - $500 \mathrm{IU}$ in anoestrus, 300 - $500 \mathrm{IU}$ in cyclic ewes) and breed (lower doses in prolific breeds) (Abecia et al., 2011).

Controlled intravaginal drug release devices are effective in inducing and synchronizing oestrous in sheep. An addition, they can release limited amounts of $\mathrm{P}_{4}$ for a longer period of time than necessary for synchronization and due to their physical characteristics the devices can be disinfected and sterilized (Ungerfeld et al., 2013; Chacher et al., 2017). However, they are costly compared with sponges, which limits their generalized use in commercial farms, and having to be disposed of after the first use causes environmental contamination owing to the residual hormone they contain (Biehl et al., 2019). For this reason, research has been conducted to determine the efficiency of induction and synchronization of oestrous with reused CIDRs in anoestrus sheep and during the reproductive season (Güngör et al., 2009; Pinna et al., 2012; Swelum et al., 2018b). Likewise, their use has been evaluated in short experiments (Cox et al., 2012; Vilariño et al., 2013; Bazzan et al., 2013) and for multiple times (Da Silva et al., 2014; Swelum et al., 2015; Swelum et al., 2018b). The devices seem to be effective in the second or third use, mainly when combined with eCG. However, there is no consensus in the literature that short procedures of oestrous synchronization improve the pregnancy rate compared with longer ones. For example, Blaschi et al. (2014) obtained a high pregnancy rate with long protocols (83.3\%) (14 days) compared with short ones (47.8\%) (5 days) and with medium duration (60\%) (9 days). On the contrary, Viñoles et al. (2001) reported greater pregnancy rate with a short protocol ( $87 \%$ ) (6 days) compared with a 12-day treatment $(67 \%)$.

Therefore, the objective of this study was to evaluate the effects on the main reproductive variables and serum progesterone concentration of primal ewes of the reuse of the CIDR device with two periods of duration (9 and 12 days) and two doses of eCG (200 and $300 \mathrm{IU})$.

\section{Material and Methods}

The study was performed in July 2018, during the season of reproductive transition (light/dark hours 13L/11D), at the experimental farm of the Colegio de Postgraduados, Campus Montecillo, México, at $19^{\circ} 29^{\prime}$ $\mathrm{N}, 98^{\circ} 53^{\prime} \mathrm{W}$ and and 2250 metres above sea level. The climate is mild, with an average annual rainfall of $632.5 \mathrm{~mm}$ in summer and an annual average temperature of between $12^{\circ} \mathrm{C}$ and $18^{\circ} \mathrm{C}$ (García, 2004). The handling of the animals was carried out according to the standards of Animal Welfare and Ethics of the Colegio de Postgraduados, México, in compliance with the Official Mexican Standard NOM-062-ZOO-1999 (SAGARPA, 2001).

In the present study, 64 primal ewes (13 months old) were used. These were a Katahdin $\times$ Suffolk hybrid, with $54 \pm 3.1 \mathrm{~kg}$ of initial bodyweight, having been dewormed with Ivomec $^{\circledR}(1 \mathrm{~mL}$ per $50 \mathrm{~kg}$ of bodyweight) subcutaneously and supplemented with Vigantol $\operatorname{ADE}^{\circledR}(1 \mathrm{ml})$ intramuscularly, with a body condition score of 3 in a score of 1 to 5 . During the experiment, all ewes were fed daily with a diet based on oat hay (Avena sativa), alfalfa hay (Medicago sativa) and $250 \mathrm{~g}$ commercial concentrate with $14 \%$ crude protein (CP). Water and mineral salts were offered ad libitum.

A device that consisted of silicon elastomers (CIDR ${ }^{\circledR}$, Zoetis, México) impregnated with $0.3 \mathrm{~g}$ natural $\mathrm{P}_{4}$ was inserted intravaginally in each ewe. The devices had previously been used in an 11-day synchronization protocol two months before the present study at the same experimental farm. The devices 
were washed with purified water after first use, dried and placed in airtight bags for refrigerated storage. One day before their second use they were exposed to room temperature to avoid moisture in the devices. At the time that the device was inserted, the vulva area was cleaned and bactericidal ointment (Furacine ${ }^{\circledR}$, PiSA, México) was applied to the applicator to prevent infection.

The ewes were randomly distributed in four treatments ( $n=16 /$ group), namely CIDR9+eCG200, CIDR9+eCG300, CIDR12+eCG200 and CIDR12+eCG300, which combine the days of duration of the device (9 or 12 days) and the dose of eCG (200 or 300 IU). The eCG hormone (Folligon ${ }^{\circledR}$ Intervet, México) was injected intramuscularly when the device was removed.

Oestrus detection began at 24 hours after the removal of the CIDR with controlled mating with males of proven fertility. They were subsequently monitored every six hours for 72 hours to determine the duration and end of the oestrous. The ewes received three mounts: the first at the start of oestrus, and two later at 12hour intervals. The return to oestrus was detected in two periods (morning and afternoon) from 15 to 18 days after mating with fertile males. The ewes that returned to oestrus received three more mounts. Pregnancy was diagnosed 30 and 60 days after the mount with a Sonovet $600^{\circledR}$ ultrasound with a $7.5 \mathrm{MHz}$ linear transrectal transducer to observe embryonic structures (Figure 1). To determine the pregnancy rate, the number of ewes that were diagnosed as pregnant was divided by the number of ewes that had been mounted. The prolificacy index was obtained by dividing the number of lambs born by the number of pregnant ewes and the type of birth by dividing the number of single or twin lambs by the number of pregnant ewes.

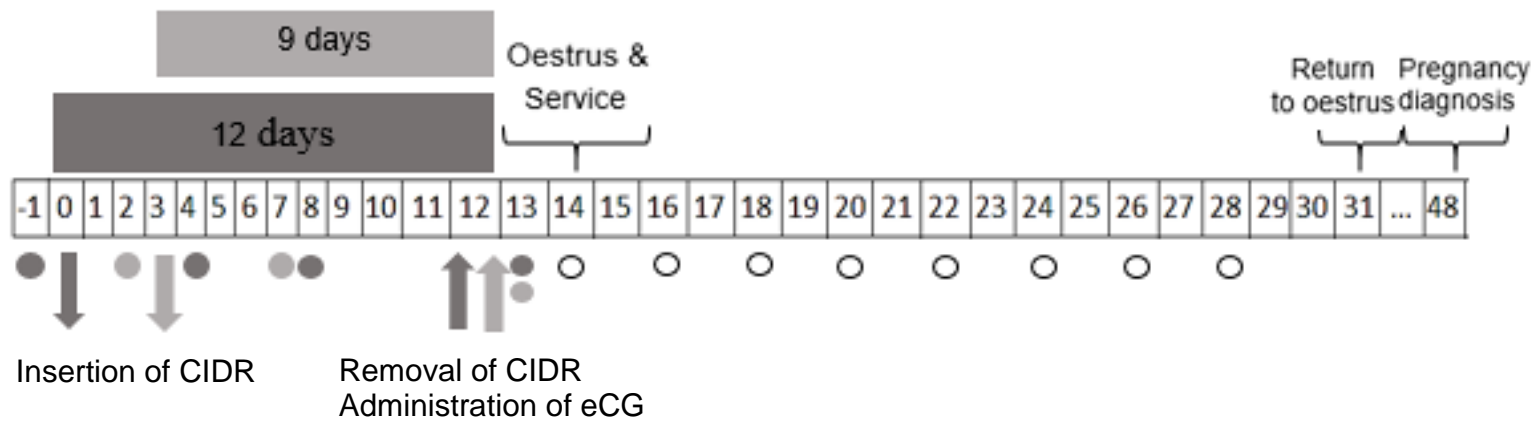

Figure 1 Experimental protocol for oestrous synchronization in ewes with a reused controlled intravaginal release device and equine chorionic gonadotrophin

O blood sample collection; CIDR: controlled intravaginal release device; eCG: equine chorionic gonadotrophin

Blood samples were collected from 10 ewes per treatment to determine the $\mathrm{P}_{4}$ levels. Samples were collected in polypropylene tubes $(5 \mathrm{~mL})$ by puncturing the jugular vein at $8 \mathrm{~h} 00$, one day before the insertion of the CIDR, on days 2, 4, 7, and 8, two days after the device was removed, and subsequently every 48 hours. All samples were centrifuged at $1500 \mathrm{~g}$ for $20 \mathrm{~min}$ at $4{ }^{\circ} \mathrm{C}$ to separate the blood serum, which was stored in Eppendorf tubes at $-20^{\circ} \mathrm{C}$ until analysis. To determine the $\mathrm{P}_{4}$ concentration, a radioimmunoassay was carried out with the commercial kit PROG-CTRIA® (Cisbio International, France) with an intra and inter assay coefficient of variation of 4.1 and 8.7 , respectively, and a sensitivity of $0.05 \mathrm{ng} \mathrm{mL}^{-1}$.

The experimental design was completely randomized with a $2 \times 2$ factorial arrangement, in which the main effects were the duration of use for the reused CIDR ( 9 and 12 days) and the level of eCG (200 and 300 IU). Data analyses were conducted using SAS, version 9.1 (SAS Institute, Inc., Cary, North Carolina, USA).. The variables of oestrous onset, return to oestrus, percentage of pregnancy, prolificacy index and type of birth were analysed with an $X^{2}$ test using PROC FREQ. Time to the beginning of oestrus and its duration, were analysed with PROC GLM and Tukey's test was used to assess differences between the treatment means. The $\mathrm{P}_{4}$ concentrations were analysed with PROC MIXED and the Tukey test was performed to determine the differences between treatment means $(P \leq 0.05)$.

\section{Results and Discussion}

Oestrus response did not differ between treatments $(P=0.285)$. However, with the dose of $200 \mathrm{IU}$ of eCG it tended $(P=0.078)$ to increase (Table 1). The high percentage of ewes that showed oestrus behaviour $(95.31 \%)$ in response to the reused CIDR suggests that in the second use CIDRs still contain enough $\mathrm{P}_{4}$ to cause LH blockage and allow the brain to respond to concentrations of circulating oestradiol, so that 
oestrous behaviour can be induced in the female (Swelum et al., 2018b). Previous studies have shown that when associated with eCG and a luteolytic agent, use for the third time in short protocols is viable for the synchronization and induction of oestrus and ovulation in ewes without affecting the percentages of oestrus presentation (Pinna et al., 2012; Bazzan et al., 2013; Vilariño et al., 2013; Da Silva et al., 2014) since the eCG favours follicular growth and the consequent production of oestradiol (Murphy, 2012).

Cox et al. (2012), using a seven-day protocol with reused CIDR with an injection of $0.125 \mathrm{mg}$ cloprostenol and $350 \mathrm{IU}$ eCG on the removal of the device, obtained $95.7 \%$ of ewes that showed oestrus in the reproductive season. These results differ from those reported by Güngör et al. (2009), who obtained $66.67 \%$ of females in oestrus when evaluating reused CIDR for 12 days plus an injection of $500 \mathrm{IU}$ of eCG in multiparous ewes in anoestrous. They also differ from those of Biehl et al. (2019), who found $70 \%$ of oestrus of in cyclic multiparous ewes with reused CIDR in protocols of 7 or 11 days plus the application of 300 IU of eCG and $6.70 \mathrm{mg}$ of Dinoprost on withdrawal of the device. Although a luteolytic agent was not used at the end of the treatment in the present study, the high percentage of oestrous response could be attributed to the use of eCG, because a greater percentage of ewes (85.94\%) showed $\mathrm{P}_{4}$ levels greater than $1 \mathrm{ng} / \mathrm{mL}$ at the beginning of the treatments, suggesting that most ewes were in a regular ovarian cycle.

Table 1 Reproductive variables in primal ewes treated with reused controlled intravaginal release device $(9 \mathrm{~d}$ or $12 \mathrm{~d}$ ) and equine chorionic gonadotrophin (200 or $300 \mathrm{IU}$ ) at device removal

\begin{tabular}{|c|c|c|c|c|c|c|c|}
\hline \multirow[b]{2}{*}{ Response variable } & \multicolumn{4}{|c|}{ Treatments } & \multicolumn{3}{|c|}{$P$-value } \\
\hline & $\begin{array}{l}\text { CIDR9 + } \\
\text { eCG200 } \\
(n=16)\end{array}$ & $\begin{array}{l}\text { CIDR9 + } \\
\text { eCG300 } \\
(n=16)\end{array}$ & $\begin{array}{c}\text { CIDR12 + } \\
\text { eCG200 } \\
(\mathrm{n}=16) \\
\end{array}$ & $\begin{array}{c}\text { CIDR12 + } \\
\text { eCG300 } \\
(n=16) \\
\end{array}$ & CIDR & eCG & $\begin{array}{c}\text { CIDR } \\
x \\
e C G \\
\end{array}$ \\
\hline Oestrus response (\%) & 100 & 87.50 & 100 & 93.75 & 0.285 & 0.577 & 0.078 \\
\hline Oestrus onset $(h)^{1}$ & $32.62 \pm 2.18$ & $30.00 \pm 2.35$ & $31.12 \pm 2.73$ & $30.80 \pm 2.50$ & 0.495 & 0.792 & 0.215 \\
\hline Oestrus duration $(\mathrm{h})^{1}$ & $36.37 \pm 3.19$ & $34.71 \pm 2.67$ & $37.12 \pm 2.94$ & $35.20 \pm 3.56$ & 0.610 & 0.574 & 0.227 \\
\hline Return of oestrus $(\%)^{2}$ & 12.50 & 18.75 & 6.25 & 6.25 & 0.629 & 0.269 & 0.691 \\
\hline Gestation $(\%)^{3}$ & 87.50 & 81.25 & 87.50 & 93.75 & 0.771 & 0.453 & 1.000 \\
\hline Lambing rate & $1.21^{b c}$ & $1.20^{\mathrm{c}}$ & $1.31^{\mathrm{ab}}$ & $1.44^{\mathrm{a}}$ & 0.001 & 0.001 & 0.823 \\
\hline$\%$ Single births & $78.57^{\mathrm{a}}$ & $66.66^{\mathrm{ab}}$ & $56.25^{\mathrm{b}}$ & $56.25^{\mathrm{b}}$ & 0.001 & 0.001 & 0.072 \\
\hline \% Twin births & $21.43^{b}$ & $26.66^{\mathrm{b}}$ & $37.50^{\mathrm{ab}}$ & $43.75^{a}$ & 0.001 & 0.001 & 0.044 \\
\hline
\end{tabular}

${ }^{a, b, c}$ Within a row, values with a common superscript do not differ with $(P=0.05)$

${ }_{1}^{1}$ Mean \pm SE of onset and duration of oestrus after withdrawal of the device

${ }^{2}$ Percentage of ewes in oestrus at 17 days after natural service

${ }^{3}$ Based on progesterone profiles in serum and ultrasound at 30 days after natural service

CIDR9 + eCG200:controlled intravaginal release device (CIDR) reused $9 \mathrm{~d}$ and 200 IU equine chorionic gonadotrophin (eCG), CIDR9 + eCG300: CIDR reused 9 d and 300 IU eCG, CIDR12 + eCG200: CIDR reused 12 d and 200 IU eCG, CIDR12 + eCG300: CIDR reused $12 \mathrm{~d}$ and 300 IU eCG

The onset and the duration of oestrus did not differ between treatments $(P>0.05)$, showing at 30 to 32 hours and lasting from 34 to 36 hours after the device was removed. These results differ from those recorded by Pinna et al. (2012), who obtained an oestrus interval of $46.1 \pm 14.1$ hours and a duration of oestrus of $52.5 \pm 1.2$ hours in ewes in anoestrous with reused CIDR for five days plus $5 \mathrm{mg}$ dinoprost and $300 \mathrm{IU}$ of eCG one day before removal of the device. Although there was no significant difference owing to the effect of the eCG dose, ewes that received 300 IU eCG showed an earlier and more compact oestrous synchrony. The addition of eCG to the new or reused CIDR protocols reduces the interval between heat and ovulation and increases the diameter of the CL on day 10 after heat (Cox et al., 2012). However, the variation in ovarian response after treatment with eCG in reproductive programmes in sheep is influenced by differences in doses, breed, nutritional level, seasonal variation, ovarian status and time of application of eCG (Shahneh et al., 2006; Rad \& Farzaneh, 2007; Moakhar et al., 2012).

For the duration of the reused CIDR devices (imitation of the luteal phase), the concentration of $\mathrm{P}_{4}$ was higher $(P<0.05)$ with the CIDR12+eCG300 treatment compared with the other groups. In all treatments, $\mathrm{P}_{4}$ concentration was maintained above $1 \mathrm{ng} / \mathrm{mL}$ and then decreased at oestrus (experimental day 14). Subsequently, $\mathrm{P}_{4}$ concentrations were higher $(P<0.05)$ with the CIDR12+eCG300 treatment only during the 
first five days after breeding (presence of functional $\mathrm{CL}$ ). The high $\mathrm{P}_{4}$ concentration in treatments with a duration of 12 days compared with nine days was probably because of a higher concentration of endogenous $\mathrm{P}_{4}$ at the beginning of the protocol and a higher rate of absorption of exogenous progestogen, which was reflected in better fertility. In addition, there is evidence of a relationship between $\mathrm{P}_{4}$ concentrations during treatments, with the ovarian follicular turnover and fertility in sheep (Vilariño et al., 2013).

Elevation of serum $\mathrm{P}_{4}$ concentration, which is influenced by the release of $\mathrm{P}_{4}$ from the device, causes persistent follicle regression and inhibits the release of gonadotropins from the anterior pituitary gland, allowing blockage of oestrus behaviour and ovulation until withdrawal of the device (Swelum et al., 2018b). Subsequently, the inhibition disappears on the removal of the device, which causes the stimulation of the gonadotropin-releasing hormone pulse from the hypothalamus, which influences the preovulatory increase of LH and FSH that results in the re-start of ovarian activity, which culminates in ovulation (Laven, 2019; Martinez-Ros et al., 2019a).

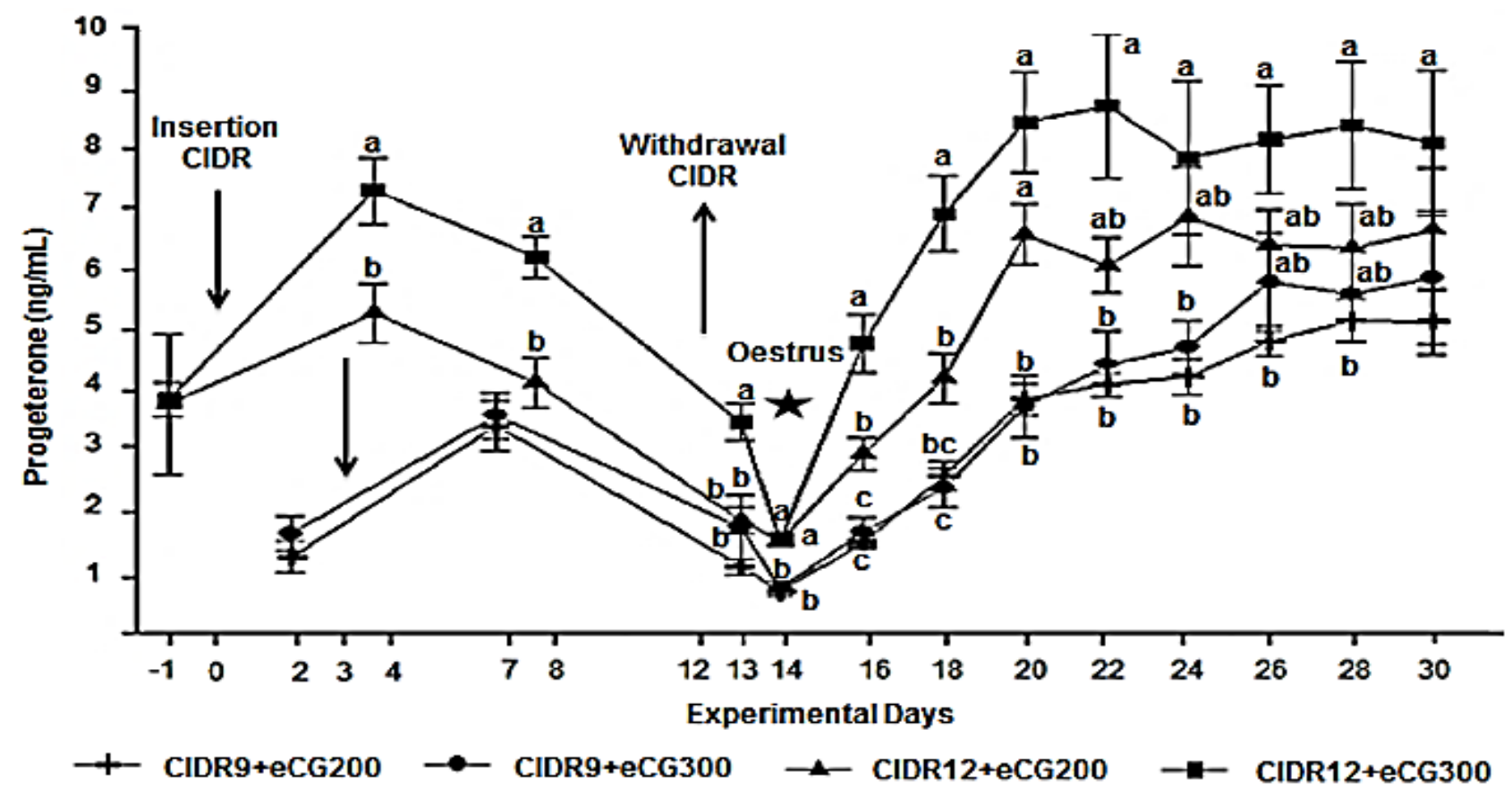

Figure 2 Progesterone concentration in serum from the insertion of the reused controlled intravaginal drug release device to its withdrawal and the posterior oestrus cycle in primal ewes

\footnotetext{
a,b,c Within a day, means with a common superscript did not differ with $P=0.05$ CIDR: controlled intravaginal drug release, eCG: equine chorionic gonadotropin CIDR9+eCG200:CIDR reused $9 \mathrm{~d}$ and $200 \mathrm{IU}$ eCG, CIDR9+eCG300: CIDR reused $9 \mathrm{~d}$ and 300 IU eCG, CIDR12+eCG200: CIDR reused $12 \mathrm{~d}$ and $200 \mathrm{IU}$ eCG, CIDR12+eCG300: CIDR reused $12 \mathrm{~d}$ and $300 \mathrm{IU}$ eCG
}

In previous work it was found that serum $\mathrm{P}_{4}$ concentrations were lower with reused devices compared with new devices. However, devices on second and third use are as effective as new ones in synchronizing oestrous and ovulation when they are used in short-term protocols in ewes in the reproductive period and in anoestrus (Cox et al., 2012; Pinna et al., 2012; Vilariño et al., 2013). On the other hand, Swelum et al. (2015), evaluated devices that were used up to six times in cyclic ewes during a short synchronization protocol, and found no differences in $\mathrm{P}_{4}$ concentration between treatments, but obtained higher percentages of induced oestrus, pregnancy, fertility and twin births with new devices and those which were only used for a second time.

The percentage of pregnancies and return to oestrus did not differ between treatments $(P>0.05)$ in the duration of the reused CIDR or the dose of eCG in primal ewes (Table 1). The ewes that showed oestrus at 17 days after natural service were served and became pregnant (except one in the CIDR9+eCG300 
treatment), which suggests that although not all the ewes were pregnant in the first oestrus, they were prepared physiologically to ovulate a healthy follicle in the second oestrus The average gestation percentage of all reused CIDR treatments was $87.50 \%$, which was higher than those reported by Da Silva et al. (2014), who evaluated the application of first-, second-, and third-use CIDR in short protocols plus the injection of $0.263 \mathrm{mg}$ of $\mathrm{PGF}_{2 \alpha}$ and $250 \mathrm{IU}$ of eCG on removal $(73.3 \%, 72.7 \%$, and $64.7 \%$, respectively) in cyclic ewes, and in those reported by Swelum et al. (2018b), who obtained $65 \%$ gestation in sheep with natural insemination in the reproductive period with CIDR devices of second use.

The results confirm what was reported by Biehl et al. (2019), who concluded that the gestation percentage is not affected by the reuse of the CIDR, in either long or short synchronization treatments when ewes are inseminated during the breeding season. They also support those of Güngör et al. (2009), who applying a long procedure with reused CIDR in ewes with natural mount in anoestrus. However, the percentage of pregnancy and fertility might be affected by the number of times that the devices have been used in the past (Swelum et al., 2015; Swelum et al., 2018b) and the type of breeding (natural or artificial insemination (Al)) (Pinna et al., 2012).

In terms of prolificacy, the CIDR12+eCG300 treatment produced the highest (1.44) number of lambs per ewe which was significantly different $(P=0.001)$ from CIDR9+eCG200 (1.21) and CIDR9+eCG300 (1.20) treatments, but not different from the CIDR12+eCG200 group (1.31). However, with the CIDR used for 12 days prolificity increased $(P=0.001)$ by $13 \%(1.37)$ relative to its use for nine days $(1.20)$. These results can be attributed to the correct development of functional $C L$ and the increase in $\mathrm{P}_{4}$ secretion to provide the endometrium with the appropriate conditions during embryo implantation and for the maintenance of pregnancy. In the CIDR9+eCG200 treatment, the abortions of two lambs in two ewes (one lamb/ewe) were presented in the last third of pregnancy.

According to Vilariño et al. (2013), there is a relationship between $\mathrm{P}_{4}$ concentrations during reused CIDR treatments, ovarian follicular turnover and fertility in ewes. In addition, Cox et al. (2012) consider that the increase in the size of the CL 10 days after oestrus in sheep treated with eCG is related to the ovulation of a greater number of healthy follicles. On the other hand, the synthesis of interferon tau (INT $)$ by the embryo is positively correlated with $\mathrm{P}_{4}$ production, so that high amounts of $\mathrm{P}_{4}$ circulating in the female, induce maternal recognition of pregnancy by increasing $\mathrm{INT}_{\mathrm{T}}$ production, which favours embryonic survival and development (Kerbler et al., 1997).

In terms of twinning, the CIDR12+eCG300 treatment obtained the highest percentage $(P=0.001)$ with $43.75 \%$. The lowest percentage was for the CIDR9+eCG200 treatment at $21.43 \%$, with no differences between this treatment and CIDR9+eCG300 and CIDR12+eCG200 (26.66\% and $37.50 \%$, respectively). The 12 days of duration of the device influenced $(P=0.001)$ the incidence of twinning births and the 300 IU dose of eCG increased $(P=0.044)$ the presentation of twinning births. This contrasts with that reported by Swelum et al. (2018b), who obtained twinning deliveries with new CIDRs (42.9\%) and CIDRs used for the second time $(63.16 \%)$ in combination with $300 \mathrm{IU}$ of eCG without statistical differences compared with devices that were used up to six times, which presented only single deliveries in sheep in the breeding season, which can be attributed to the greater number of mature ovulated follicles during oestrus. In addition, previous studies have shown that the characteristics of the ovulatory follicle and the subsequent luteal phase do not differ among sheep treated with first, second and third use of devices (Pinna et al., 2012; Vilariño et al., 2013). On the other hand, the addition of eCG to ewe synchronization programmes increases the ovulation rate, which triggers multiple births in a greater proportion (Murphy, 2012).

\section{Conclusions}

Use of a CIDR device for a second time in primal ewes results in sufficient relaease of progesterone to synchronize oestrous, which allows the use of CIDR devices to be maximized. The best results in reproductive efficiency in the prolificity index and twinning deliveries were obtained when the reused CIDR was inserted for 12 days with $300 \mathrm{IU}$ of eCG injected upon its removal.

\section{Authors' Contributions}

YIRS was an MSc student in the project. TST, JLCM, JLFV, JCZ, AMA, and MCL were responsible for the design and execution of the project. All co-authors participated in the management and discussion of the results, statistical analysis and writing, and correction of the manuscript. MCL ran the hormonal analysis.

\section{Conflict of Interest Declaration}

There are no conflicts of interest.

\section{References}

Abecia, J. A., Forcada, F. \& González-Bulnes, A., 2011. Pharmaceutical control of reproduction in sheep and goats. Vet. Clin. N. Am-Food A. 27, 67-79. DOI: 10.1016/j.cvfa.2010.10.001. 
Abecia, J.A., Forcada, F. \& González-Bulnes, A., 2012. Hormonal control of reproduction in small ruminants. Anim. Reprod. Sci. 130(3-4), 173-179. DOI: https://doi.org/10.1016/j.anireprosci.2012.01.011.

Barret, D.M.W., Bartlewski, P.M., Batista-Arteaga, M., Symington, A. \& Rawlings, N.C., 2004. Ultrasound and endocrine evaluation of the ovarian response to a single dose of $500 \mathrm{UI}$ of eCG following a 12-day treatment with progestogen releasing intravaginal sponges in the breeding and nonbreeding season in ewes. Theriogenol. 61(13), 311-327. DOI: https://doi.org/10.1016/S0093-691X(03)00215-2.

Bartlewski, P.M., Sohal, J., Paravinja, V., Baby, T., Oliveira, M.E.F., Murawski, M., Schwarz, T., Zieba, D.A. \& Keisler, D.H., 2017. Is progesterone the key regulatory factor behind ovulation rate in sheep? Domest. Anim. Endocrinol. 58, 30-38. https://www.researchgate.net/publication/304711950

Bazzan, A.P., Tedesco, D., Menestrina, A.L., Machado, S.A., da Rocha, R.X. \& Bragança, J.F.M., 2013. Re-utilization of an intravaginal device with progesterone in the induction/synchronization of estrus in the sheep. RPCV. 108 (587588), 143-146. https://www.researchgate.net/publication/264346429. Accessed 12 August 2019. (In Portuguese, English abstract).

Biehl, M.V., de Ferraz Junior, M.V.C., Barroso, J.P.R., Susin, I., Ferreira, E.M., Polizel, D.M. \& Pires, A.V., 2019. The reused progesterone device has the same effect on short or long estrus synchronization protocols in tropical sheep. Trop. Anim. Health Prod. 51(6), 1545-1549. DOI: https://doi.org/10.1007/s11250-019-01841-1.

Blaschi, W., Lunardelli, P.A., Marinho, L.S.R., Max, M.C., Santos, G.M.G., Silva-Santos, K.C., Melo-Sterza, F.A., Baldassarre, H., Rigo, T.R. \& Seneda, M.M., 2014. Effects of progestogen exposure duration on estrus synchronization and conception rates of crossbreed ewes undergoing fixed time artificial insemination. J. Vet. Sci. 15, 433-437. DOI: 10.4142/jvs.2014.15.3.433.

Chacher, M.F.A., Çolak, A. \& Hayirli, A., 2017. Efficacy of repeatedly used CIDR device in cattle reproduction: a metaanalysis review of progesterone concentration and conception rate. Turk. J. Vet. Anim. Sci. 41, 692-697. DOI: 10.3906/vet-1706-75.

Cox, J.F., Allende, R., Lara, E., Leiva, A., Díaz, T., Dorado, J. \& Saravia, F., 2012. Follicular dynamics, interval to ovulation and fertility after Al in short-term progesterone and PGF2 $\alpha$ oestrous synchronization protocol in sheep. Reprod. Domestic Anim. 47(6), 946-951. DOI: 10.1111/j.1439-0531.2012.01996.x.

Da Silva, T.B., da Rocha, J.F.X., Machado, S.A., da Rocha, R.X., Bennemann, P.E. \& Bragança, J.F.M., 2014. A reutilização de um dispositivo intravaginal (CIDR-G) nas manifestações de estro e prenhez da espécie ovina. Enciclopédia biosfera, 10(18), 40-45. Available at: https://www.researchgate.net/publication/264346429. Accessed 10 August 2019. (In Portuguese, English abstract).

Escobar, E.N., Kassa, E., O’Brien, D. \& H. Taylor., 2017. The induction and synchronization of estrus in sheep during the fall and late spring (season and out of season) using controlled internal drug release (CIDR) devices on Delmarva. J. Anim. Sci. 95(suppl_4), 39. DOI: https://doi.org/10.2527/asasann.2017.078.

García, E., 2004. Modifications to the system Köppen climate classification. 5th edition. Book series 6 . Institute of Geography, Universidad Autóno,ma de México.

Ginther, O.J., Kot, K. \& Wiltbank, M.C., 1995. Associations between emergence of follicular waves and fluctuations in FSH concentrations during the estrous cycle in ewes. Theriogenology 43, 689-703.

Güngör, Ö. Özyurtlu, N., Pancarci, S.M., Kaya, M., Zonturlu, A.K., Oral, H., Çetin, Y. \& Polat, B., 2009. Estrous synchronization with used CIDR-G devices in ewes during non-breeding season. Kafkas Univ. Vet. Fak. Derg. 15(5), 779-783. Available at https://www.researchgate.net/publication/234127359 Accessed 13 August 2019. (In Turkish, English abstract).

Kerbler, T.L., Buhr, M.M., Jordan, L.T., Leslie, K.E. \& Wlaton, J.S., 1997. Relationship between maternal plasma progesterone concentration and interferon tau synthesis by the concepts in cattle. Theriogenology 47, $703-714$. DOI: https://doi.org/10.1016/S0093-691X(97)00028-9

Laven, R., 2019. Pharmacological agents in the control of Reproduction. In: D.E. Noakes, T.J. Pakinson \& C.W. England (eds). Veterinary reproduction and obstetrics. Saunders Ltd., Philadelphia, Pennsylvana, USA. pp. 157-166.

Martinez-Ros, P., Rios-Abellan, A. \& Gonzalez-Bulnes, A., 2019a. Influence of progesterone-treatment length and eCG administration on appearance of estrous behavior, ovulatory success and fertility in sheep. Animals 2019, 9, 9. doi:10.3390/ani9010009.

Martinez-Ros, P., Gonzalez-Bulnes, A., Garcia-Rosello, E., Rios-Abellan, A. \& Astiz, S., 2019b. Effects of short-term intravaginal progestagen treatment on fertility and prolificacy after natural breeding in sheep at different reproductive seasons. J. Appl. Anim. Res. 47(1), 201-205. DOI: 10.1080/09712119.2019.1599899

Menchaca, A. \& Rubianes, E., 2004. New treatments associated with timed artificial insemination in small ruminants. Reprod. Fertil. Dev. 16, 403-413. DOI: 10.1071/RD04037

Menchaca, A., Neto, P.C.S. \& Cuadro, F., 2017. Estrous synchronization treatments in sheep: Brief update. Rev. Bras. Reprod. Anim. 41(1), 340-344. https://www.researchgate.net/publication/317368326 Accessed 13 August 2019.

Moakhar, H.K., Kohram, H., Shahneh, A.Z. \& Saberifar, T., 2012. Ovarian response and pregnancy rate following different doses of eCG treatment in Chall ewes. Small Ruminant. Res. 102, 63-67. DOI: 10.1016/j.smallrumres.2011.09.017.

Mohan, K.M., 2017. Progesterone concentration in ewes synchronized with controlled internal drug releasing (CIDR) device. Pharma Innovation J. 6(4), 72-74

Murphy, B.D., 2012. Equine chorionic gonadotropin: An enigmatic but essential tool. Anim. Reprod. 9(3), $223-230$. Available at: https://www.animal-reproduction.org/article/5b5a6057f7783717068b46e2 Accessed 10 August 2019.

Pinna, A.E., Brandão, F.Z., Cavalcanti, A.S., Borges, A.M., Souza, J.M.G. \& Fonseca, J.F., 2012. Reproductive parameters of Santa Inês ewes submitted to short-term treatment with re-used progesterone devices. Arq. Bras. Med. Vet. Zootec. 64(2), 33-340. DOI: 10.1590/S0102-09352012000200012 
Rad, A.H.F. \& Farzaneh, N., 2007. Effect of CIDR and different doses of PMSG on pregnancy and lambing rate out of breeding season in Balouchi ewes. J. Anim. Vet. Adv. 6(10), 1157-1171. Available at: http://medwelljournals.com /abstract/?doi=javaa.2007.1167.1171 [Accessed 10 August 2019]. DOI: javaa.2007.1167.1171

Ramos, A.F. \& Silva, B.D.M., 2018. Hormonal protocols in small ruminants. In: T.G. Bergstein-Galan (ed). Reproduction biotechnology in farm animals. AvidScience, Telangana, India. pp. 138-154.

Rosa, H.J.D. \& Bryant, M.J., 2003. Seasonality of reproduction in sheep. Small Ruminant Res. 48, 155-171. DOI:10.1016/S0921-4488(03)00038-5

SAGARPA, Secretaría de Agricultura, Ganadería, Desarrollo Rural, Pesca y Alimentación., 2001. Norma Oficial Mexicana NOM-062-ZOO-1999, Especificaciones técnicas para la producción, cuidado y uso de los animales de laboratorio. Diario Oficial de la Federación. 75, 113-160.

Shahneh, A.Z., Tajangookeh, H.D., Panah, H.S. \& Saki, A.A., 2006. Effect of controlled internal drug release device treatment duration and eCG dose on reproductive performance of seasonally anestrous fat-tailed Iranian ewes. Pak. J. Biol. Sci. 9(8), 1552-1555. DOI: 10.3923/pjbs.2006.1552.1555

Swelum, A.A., Moumen, A.F. \& Alowaimer, A.N., 2015. Effect of six times reusing of controlled internal drug release (CIDR) for short term (6 days) on progesterone level and reproductive performance of Awassi ewes. Reprod. Fertil. Dev. 28, 136-136. DOI: 10.1071/RDv28n2Ab13

Swelum, A.A., Moumen, A.F. \& Alowainer, A.N., 2016. The effect of withdrawal timing of controlled internal drug release (CIDR) on ewe reproductive performance. Reprod. Fertil. Dev. 19, 119-119. DOI: 10.1071/RDv29n1Ab23

Swelum, A.A., Saadeldin, I.M., Moumen, A.F., Ali, M.A. \& Alowaimer, A.N., 2018a. Efficacy of controlled internal drug release (CIDR) treatment durations on the reproductive performance, hormone profiles, and economic profit of Awassi ewes. Small Ruminant. Res. 166, 47-52. DOI: 10.1016/j.smallrumres.2018.07.018.

Swelum, A.A., Saadeldin, I.M., Moumen, A.F., Ali, M.A., Ba-Awadh, H. \& Alowainer, A.N., 2018b. Efficacy of using previously used controlled internal drug release (CIDR) insert on the reproductive performance, hormone profiles and economic measures of sheep. Reprod. Domestic. Anim. 53(5), 1114-1122. DOI: $10.1111 /$ rda.13212.

Ungerfeld, R., Gamboa, D. \& Álvarez,L., 2013. Response of ewes primed with new CIDRs, previously used CIDRs, or previously used and autoclaved CIDRs to the ram effect during the non-breeding season. Anim. Repro. 10(4), 704-707. Available at: https://www.animal-reproduction.org/article/5b5a6046f7783717068b4683

Uriol, M., Martínez-Ros, P., Rios, A., Encinas, T. \& Gonzalez-Bulnes, A., 2019. Onset of oestrus and periovulatory events in sheep exposed to 5 and 14 days of CIDR treatment with and without eCG. Repro. Domestic Anim. 54, 1489-1492. DOI: 10.1111/rda.13537.

Vilariño, M., Rubianes, E. \& Menchaca, A., 2013. Ovarian responses and pregnancy rate with previously used intravaginal progesterone releasing devices for fixed-time artificial insemination in sheep. Theriogenology 79(1), 206-310. DOI: 10.1016/j.theriogenology.2012.10.007.

Viñoles, C., Forsberg, M., Banchero, G. \& Rubianes, E., 2001. Effect of long-term and short-term progestogen treatment on follicular development and pregnancy rate in cyclic ewes. Theriogenology 55, 993-1004. DOI: 10.1016/S0093-691X(01)00460-5.

Wheaton, J.E., Carlson, K.M., Windels, H.F. \& Johnston, L.J., 1993. CIDR: A new progesterone-releasing intravaginal device for induction of estrus and cycle control in sheep and goats. Anim. Reprod. Sci. 33(1-4), 127-141. DOI: 10.1016/0378-4320(93)901114. 